\title{
Deep Learning Based on Wireless Remote Sensing Model for Monitoring the Solar System Inverter
}

\author{
Xiaoyan Wang ${ }^{1}$ and Gaokui $\mathrm{Xu}^{2}$ \\ ${ }^{1}$ Southwest Forestry University School of Mathematics and Science, Kunming, China \\ ${ }^{2}$ Kunming Railway Vocational and Technical College, Kunming, China \\ Correspondence should be addressed to Xiaoyan Wang; 849612371@swfu.edu.cn
}

Received 19 February 2021; Revised 9 April 2021; Accepted 18 April 2021; Published 14 July 2021

Academic Editor: M. Irfan Uddin

Copyright (c) 2021 Xiaoyan Wang and Gaokui Xu. This is an open access article distributed under the Creative Commons Attribution License, which permits unrestricted use, distribution, and reproduction in any medium, provided the original work is properly cited.

\begin{abstract}
Traditional energy sources have become one of the most serious causes of environmental pollution because of the growing demand for energy. Because of the carbon emissions that have recently increased greatly, we had to search for a safe, cheap, and environmentally friendly energy source. Many photovoltaic (PV) solar panels are used as an energy source because of free and environmental friendliness. However, this technology has become a source of inspiration for many researchers. The proposed method suggests to extract useful features from PV and wind generators and then train the system to control them and update the inputs according to prediction results. Solar energy produces energy that varies according to the external influences and the immediate changes in weather conditions. Solar panels are connected through an inverter with the grid, through which the work of the solar panels is monitored using the Internet. It is worth using neural networks $(\mathrm{NN})$ to control variables and adopt system output of previous iteration in processing operations. Use of deep learning (DL) in the control of solar energy panels helps reduce the direct surveillance of the system online. Solar power generation systems mainly depend on reducing the pollution resulting from carbon emissions. Saving $\mathrm{CO}_{2}$ emission is the main purpose of PV panel cells, so smart monitoring can achieve better result in that case.
\end{abstract}

\section{Introduction}

With regard to the increasing population density, which has become uncontrollable, consequently, the requirements of life have increased according to technological development. The electric power network is one of the largest and most complex networks that supply electrical energy to citizens, so there must be economic feasibility in transmitting and generating this energy [1]. It is imperative to provide the increasing demand for electric power with the lowest acceptable cost in order to reach the level of environmental safety [2].

Therefore, it is imperative to plan future needs for electricity taking into account the integration resources of environmentally friendly energy and to ensure that sufficient reserves are in place to meet the load demand increasing [3]. It is imperative to maintain the reliability of electricity, the absence of interruptions in electricity services, and the integration of citizens with government agencies. Studying a clean and alternative power generation system and equipping it properly is the main purpose of this study.

Three main issues that control the electrical system are as follows. First is power generation. Generation comes on the main level in terms of importance. The second issue that controls the supply of electrical energy is the transmission which is responsible for transmit the power from source generating to the destination demands [4]. The third issue that affects the electrical system is the uniform distribution between local networks. Since our study includes controlling the solar energy generation system, therefore, we must take into consideration the three issues that determine electrical energy [5].

The increase in pollution results from burning fuels due to the increasing demand for electric power in addition to 
the generation of harmful gases, such as $\mathrm{CO}_{2}$, that cause contamination of the environment [6]. Therefore, modern methods of generating electrical energy, which are environmentally friendly, are used; solar energy is one of these methods and has a very high efficiency, at the present time. The carbon emission in 2013 was 32.2 billion tons, which increased over the record in 1990, which reached a maximum of $56.1 \%$, and also in 2012 , its percentage was more than $2.3 \%$. Therefore, the use of alternative clean energy is a major reason for reducing carbon emissions [7]. Solar cell technology has increased nowadays due to increasing technological development. New technologies enable us to control the efficiency of energy generation in this context which can be exploited in the smart home, and deep learning is a technology that uses smart technology in smart cities [8]. Any system including the PV system when managed by deep learning should be understood first in order to get utmost benefit. Training such system is not easy and needs more experience and costs time under fixed conditions [9]. Due to the proposed system which is managed remotely, we have to train the remote-sensing system to be able to adapt with the deep learning system. It is worth using electric grid of the energy when neural network (NN) system is used and run accordingly.

Many existing studies have contributed in remote monitoring of solar energy and solar cell power generation. Table 1 summarizes the most important studies in this field.

The research is structured as follows. Section 1 gives definition and introduction for the techniques and used tools. Section 2 introduces energy systems such as solar and wind generator. Section 3 introduces the techniques that will be used in the proposed method. The proposed method is discussed in detail Section 4. Then, result analysis is illustrated in Section 5 for analysis and discussion. Finally, Section 6 at the end of the research gives proper summary of the research.

\section{Solar and Electrical Energy System}

Electrical energy is obtained from solar energy by using PV cell. The PV cell can be defined as a converter of light obtained from the source energy into electricity directly via photovoltaic effect [17], as shown in Figure 1.

Many variables when using photovoltaic cells can be taken into consideration such as voltage, current, resistance, and time. PV panels consist of a number of solar cells combined together to form a module [18]. PV silicone when exposed under sunlight generate Volte around 0.5 to 0.6 Volte. The PV cell can be used as a photodetector which can sense light or electromagnetic radiation and measure light intensity. Maximum Power Point Tracking (MPPT) is an algorithm that is usually used with PV to extract maximum power under all conditions. Output energy gain is based on the relation between temperature and resistance in the nonlinear manner. The relation between produced $\mathrm{I}$ and $\mathrm{V}$ affects the efficiency of the PV system.. Maximum load is determined by external environment effect such as temperature and proper gain. MPPT, sometimes, is called increment conductance, constant voltage, or temperature technique.
Each structure of solar power generator is classified based on converters' design, which is PV commercial available. Three classes, according to inverter distribution, are centralized inverters, microinverters, and string inverters [19]. Structure of string and central PV system is almost similar based on the distribution of the inverter inside the grid or array. The connecting inverter inside the solar array reflects the manner of designing the Solar System. Connecting the inverter to the array of photo cells in both string and central somewhat is costly but worthy. In this study, we consider the central PV system, as shown in Figure 2.

PV solar cell is arranged as the array to connect through the system and invertor and consider the main issue in monitoring.

\section{Deep Learning}

With the development in data science and modern technology, such as big data and high-performance computers, an opportunity is provided for machine learning to understand data and behavior of it through complex systems. Machine learning gives the machine the ability to learn in different algorithms without strict orders from a certain program or limited instruction [20].

Deep learning can be defined as a technique of machine learning to learn useful features directly from given images, sounds, and texts. Many layers are exploited by deep learning for nonlinear data processing of unsupervised or supervised feature extraction for classification and pattern recognition. Deep learning motivation is greatly reduced by artificial intelligence (AI) area, which simulate the ability of the human brain in terms of analyzing, making decision, and learning [21]. Deep learning goal is to emulate approach of hierarchical learning of extracting features by the human brain directly from unsupervised data.

The core of deep learning hieratically computed the features and representation of information, such as defining the features starting from the low level to the high level [22]. Many applications are provided by the tolls of machine learning [23]. With the normal solar PV system, the standard techniques of machine learning do not work well when running directly because of ignoring the nature of grid distribution. Deep learning features are extracted automatically from the given PV solar invertor. The characteristics of this method of features are considered in one of the learning in the system.

Characterization of input data used as a feature is the key issue to success of processing PV system. There are limitations during control and monitoring PV solar system. For this reason, we can use deep learning by its feature extraction to solve limitation in such field.

As mentioned before, the main difference between machine learning and deep learning is the features' selection method [24], as shown in Figure 3.

Features in deep learning will be generated automatically to simulate the appropriate results. Different hidden layers participate in decision-making by using the feedback from the next layer that will feed back to the previous layer [25]. DL enables computers to perform complex calculations by 
TABLE 1: Most important studies in literature which considered remote monitoring of solar energy.

\begin{tabular}{lcc}
\hline Authors & Method & Achievement \\
\hline$[10]$ & Examined grid connected domestic PV array & High extra solar power store in the battery \\
{$[11]$} & Battery storage EMS for a rooftop PV system & Increase daylight power even when cloud \\
{$[12]$} & Grid connected hysteresis current control solar PV & Current, inverter track, and current of solar PV system \\
{$[13]$} & Photovoltaic with storage devices (lead-acid battery) and AI & Maximum remote sensing of PV \\
{$[14]$} & system & More control on temperature \\
{$[15]$} & Effective optimization algorithm by web monitoring & Control over large area \\
{$[16]$} & Internet of things (IoT) & Enhances the maintenance and the performance of the \\
\end{tabular}

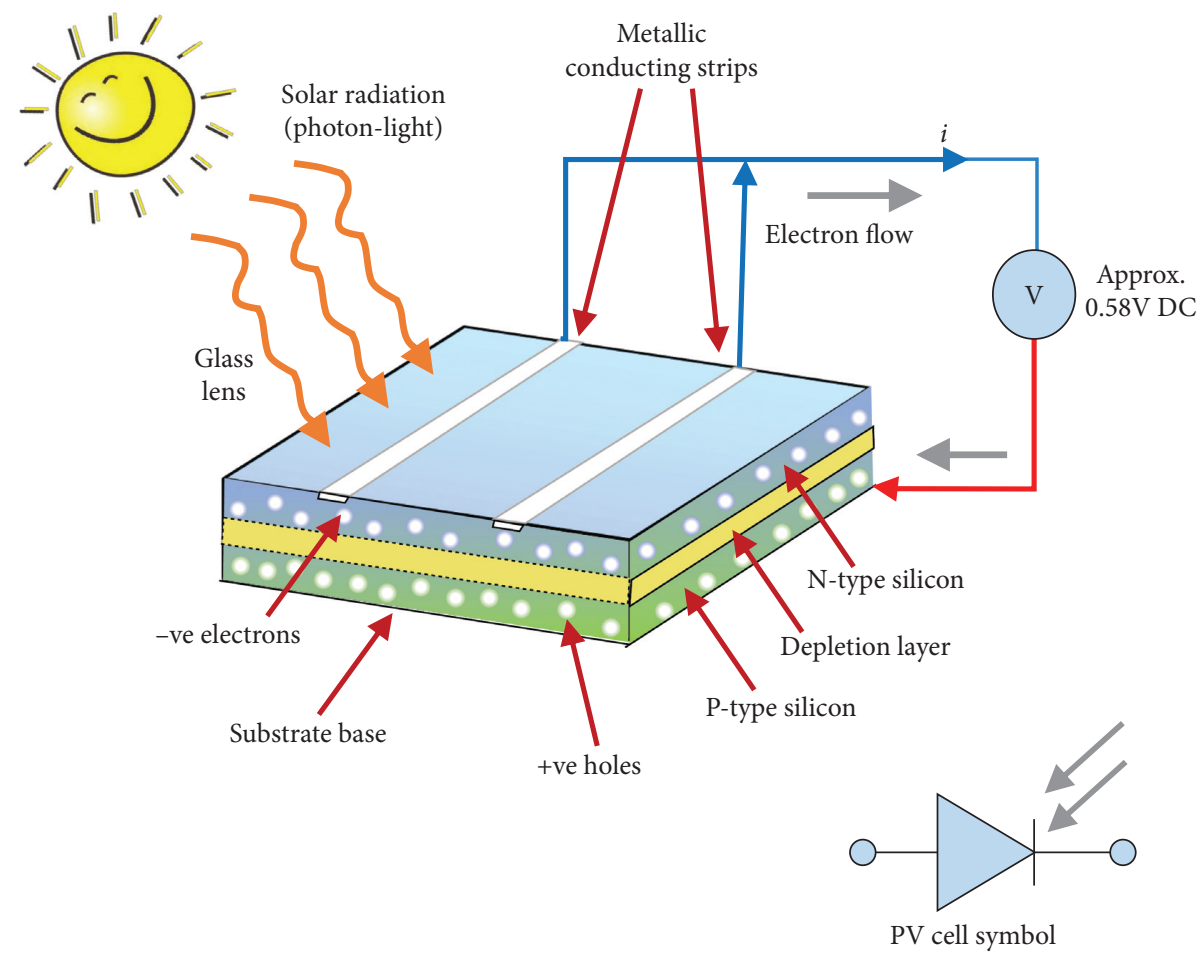

Figure 1: How PV converts light to electricity?

relying on simpler calculations to optimize computer efficiency [26]. It is difficult for a computer to understand complex data such as national or PV grids (under certain environments) or a series of data of a complex nature, so we use deep learning algorithms instead of usual learning methods [27].

\section{Proposed Method}

Day by day the demand for electricity is increasing. Owing to deficit in the fuels, especially in poor countries, and the harms to the environment caused by power generation, solar energy is becoming very popular and demanding. This kind of energy is considered free from pollution and is also available free of cost all over the world. Due to its free availability, we need to consider this power source and improve the solar energy monitoring to get the optimal performance. Remote monitoring already exists, and there is need to improve optimal load performance and scheduling. The proposed diagram for monitoring PV panels is displayed in Figure 4.

There are many methods for monitoring and acquisition; the data are listed as follows:

(i) Wired monitoring: by this technique, wire is used to gather information of automatic transmission and then used to measure the data remotely from the sender to the receiver by wire communication. Wireless monitoring aims to avoid any physical communication and remotely control and record the results.

(ii) SCADA: it is a system aiming to control the grid remotely from different locations, and real time is important here. 

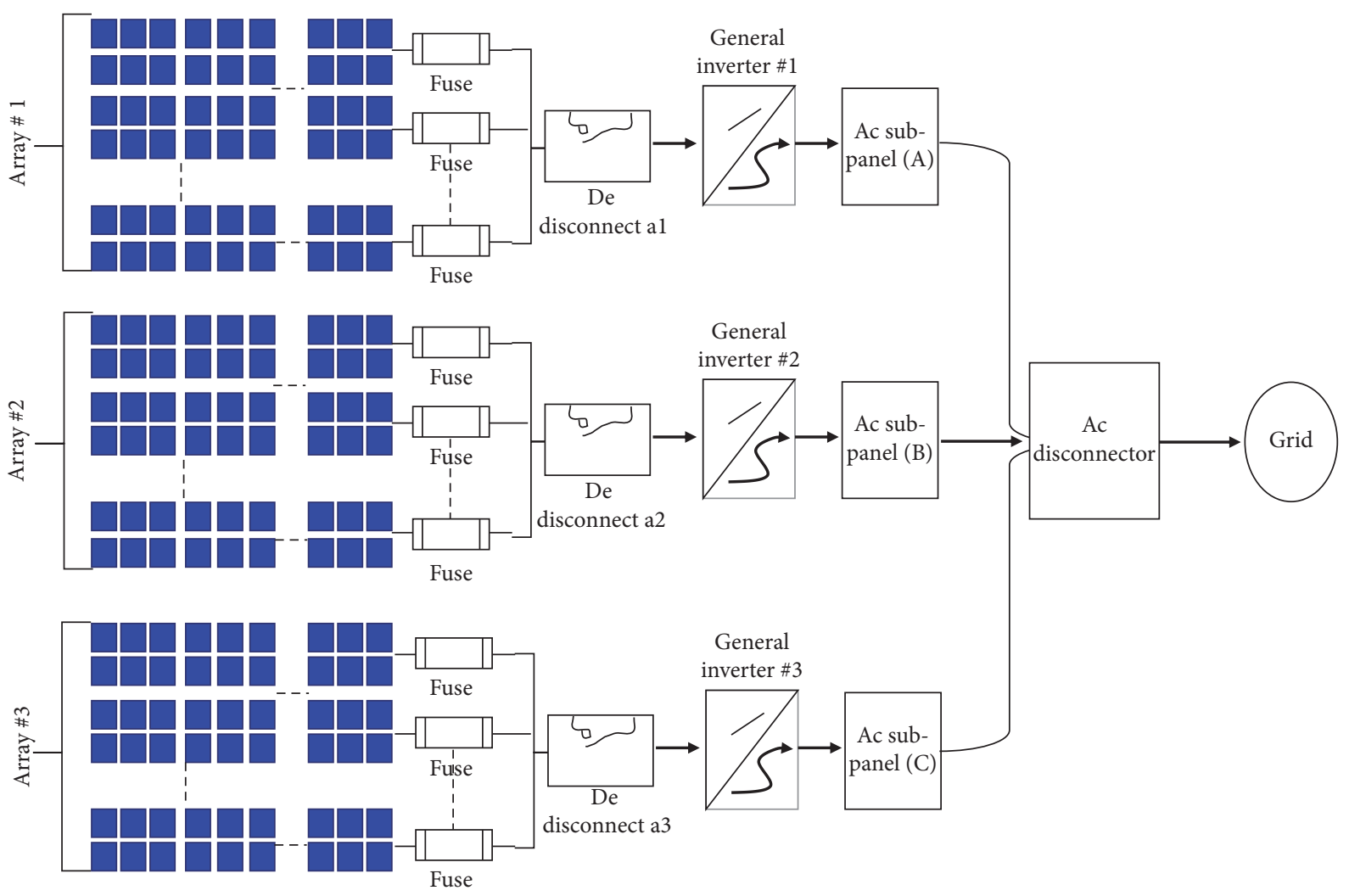

FIGURE 2: Invertor structure in central class.

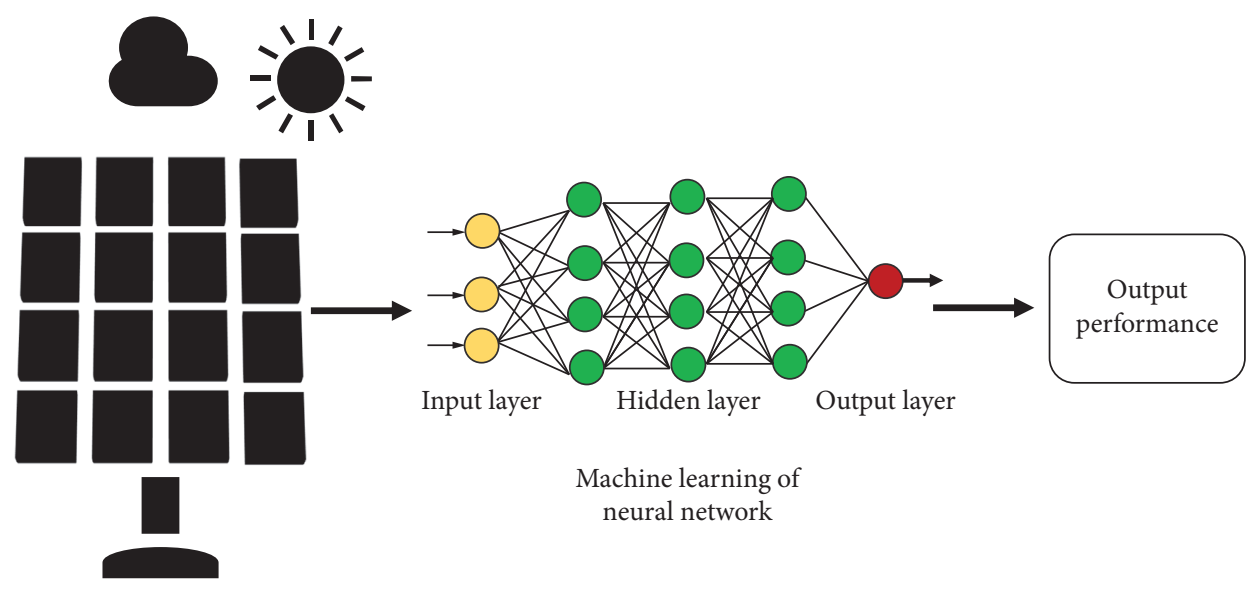

PV solar cells

FIGURE 3: Deep learning system of PV solar cells.

(iv) Cloud computing monitoring: it is based on a computer system and the demand from the local or a remote location which aims make data available over the Internet and control remotely.

(v) IOT monitoring (Internet of things): it is carried out using physical connection devices on the Internet and connecting other devices or any hardware in such case monitoring will be remote as well as under control.
In this study, we focus on clouding monitoring that uploading data over the cloud is necessary so it can request them anytime and anywhere.

In terms of feature extraction from given parameters, we have to update the parameters' weights every day. Neural network (NN) is designed to be adaptive with fixed and variable parameters such as results or decision may be fed again to other hidden layers as input. Many parameters are 


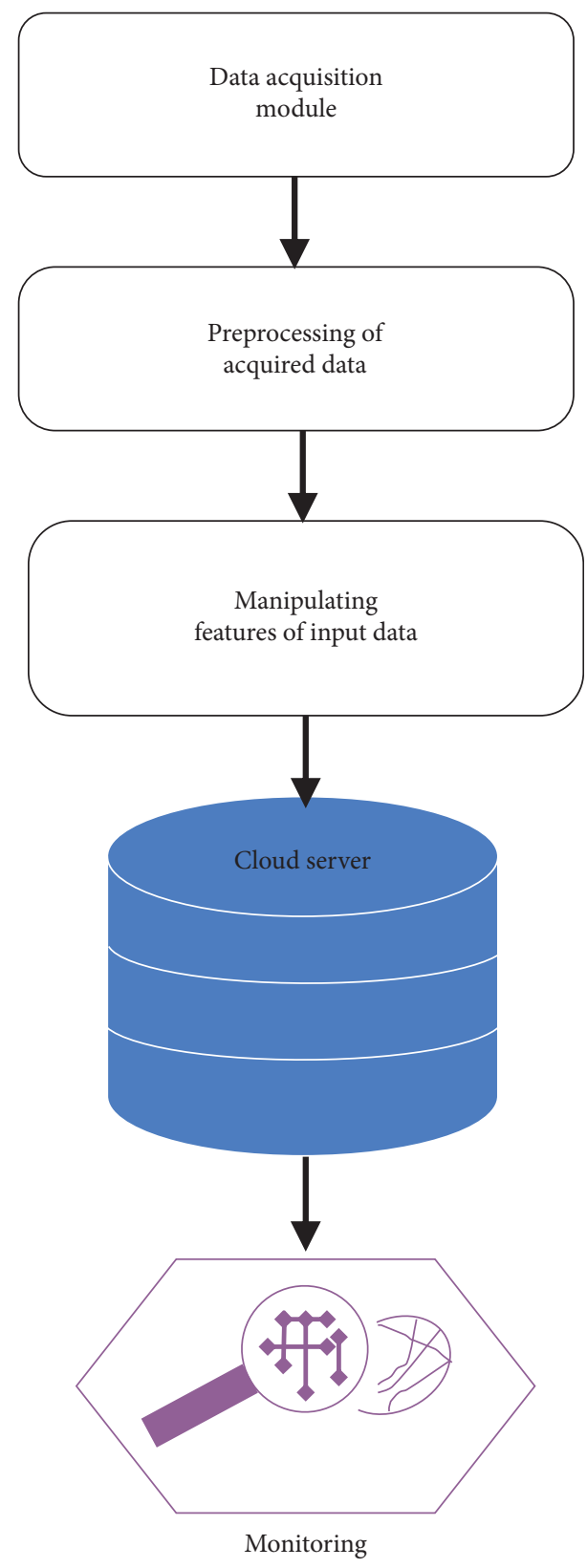

Figure 4: Diagram of the proposed method.

taken into consideration, such as winds, sun direction, temperature, and clearance of the air.

Any variable, no matter how small, must be taken into account by the proposed system, such as angle of sunlight or humidity, as shown in Figure 5.

As for the angle of inclination, it is chosen to obtain the highest intensity of solar radiation, especially in the summer, and we know that the sun rises at a large angle of elevation and gradual, which means there will be more than one value, not the energy output depending on the angle; the system, as we mentioned, is of the fixed type that does not move with the sun (no tracking), where the angle of inclination ranges from zero degrees horizontally to 90 degrees vertically.

Figure 6 illustrates how to calculate the angles according to sun light direction movement.
Height of the panel and its angle can be found from the following equation:

$$
\begin{aligned}
& x=\operatorname{Sin} \text { Tilt }^{\circ} \times \text { length }, \\
& y=x \times \frac{\operatorname{Cos}(\text { azimuth angle })}{\text { Tan (altitude angle })}
\end{aligned}
$$

where (Tilt) ${ }^{\mathrm{o}}$ represents the angle of the panel with horizontal ground, which is variable according to the time.

Connecting the invertor to the web through WIFI network, all information regarding the grid of the PV solar panel is updated simultaneously. The invertor is responsible for modulation of the power obtained from panels to the grid or the end user. Therefore, all data collected from outside or inside the system are used as features in addition to the result data to accumulate information and updated parameters supervised by the system automatically and end operator monitoring through the web.

The proposed system aims to increase the performance of PV solar cells and reduce the fuel consumption in addition to controlling or saving $\mathrm{CO}_{2}$ emission, which is explained in detail in Section 5.

For better illustration of the proposed method, the whole system is summarized in Figure 7.

The deep learning method is based on how to extract the features and quality of them. In green energy and proposed method, we used two types of green energy generators which are solar and wind. In the proposed method, we considered many features to learn the system and then choose the appropriate results in terms of control.

\section{Experimental Results}

The proposed system allows us to make complex computation for better evaluation. Most of PV panel cells' system aims to reduce the cost, both commercially and environmentally. For this reason, our study was proposed. Firstly, cost of generation reduced by using deep learning (DL) due to the system simulates the whole environment and makes decision immediately without the need for online monitoring. Training of the system begins with offline grid and with a system of 38 invertors. The system automatically adopts the structure of PV panels, as shown in Figure 8.

Energy produced from solar panels within on-grid goes through the main grid, generating part of demanding power. Therefore, the consumption of diesel generators will be reduced due to the lower loads.

Another goal of the research is to reduce $\mathrm{CO} 2$ emissions. Solar generators are known to be environmentally friendly, so they contribute very greatly to reduce environmental pollution. Figure 9 shows how the system participates to save the environment.

The efficiency of the system is measured in terms of saving the society and the environment, in addition to the important factor: the material cost. Tables 2 and 3 also show 
Field type Fixed Tilted Plane

Field Parameters

$$
\begin{gathered}
\text { Plane Tilt } \sqrt{30.0} \div\left[^{\circ}\left[{ }^{\circ}\right]\right. \\
\text { Azimuth } 0.0 \div\left[{ }^{*}\right]
\end{gathered}
$$

Dptimisation by respect to

(6) Yearly irradiation yield ?

(C) Summer (Apr-Sep)

C Winter [Oct-Mar]

\section{Tilt $30^{\circ}$}
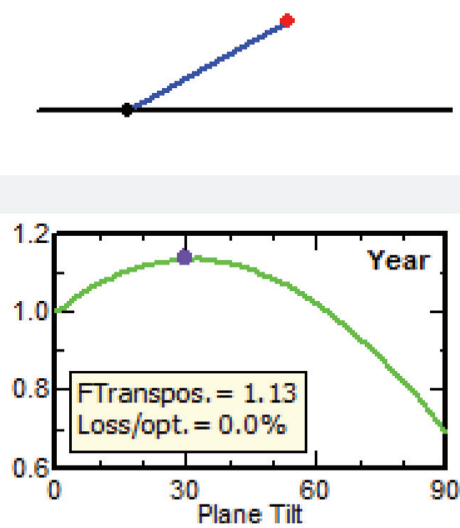

\section{Azimuth $0^{\circ}$}
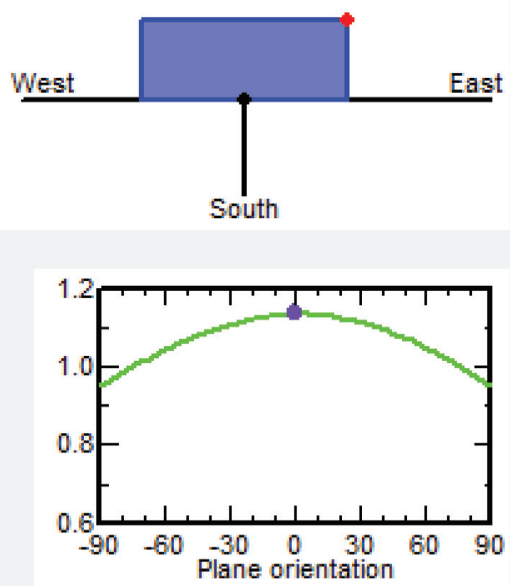

\section{$\mathbf{X}$ Cancel}

\section{DK}

FIGURE 5: Sunlight angles changing throughout the day.

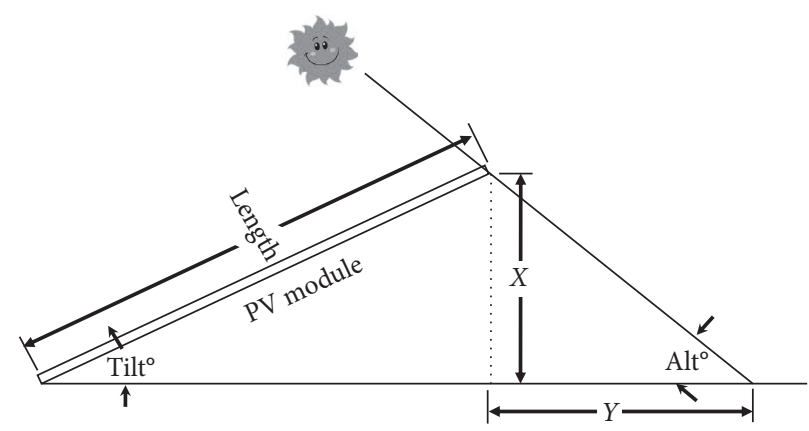

Figure 6: Direction of PV solar panel under the sun.

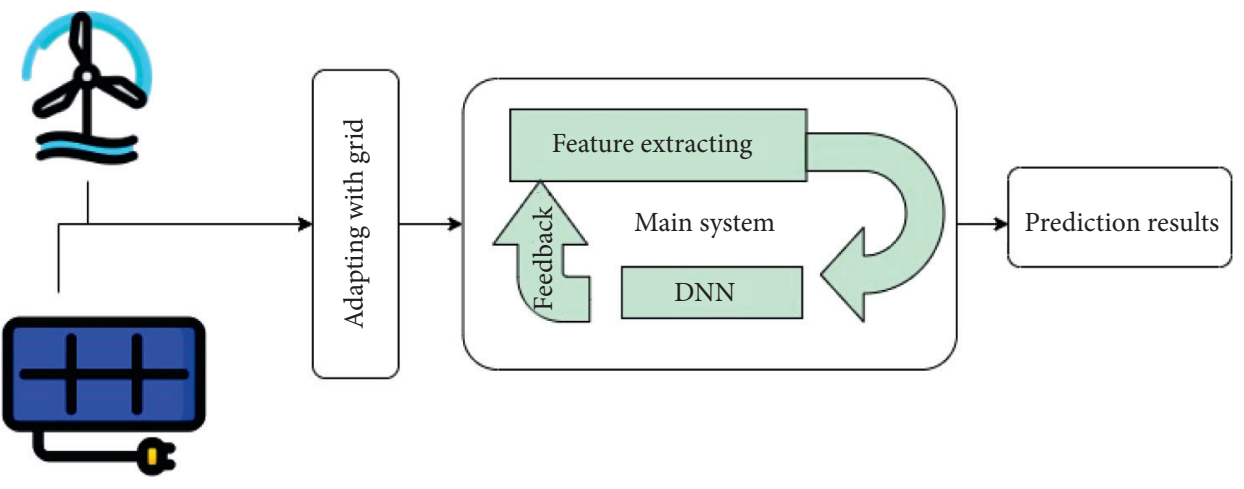

Figure 7: The proposed method within the system. 


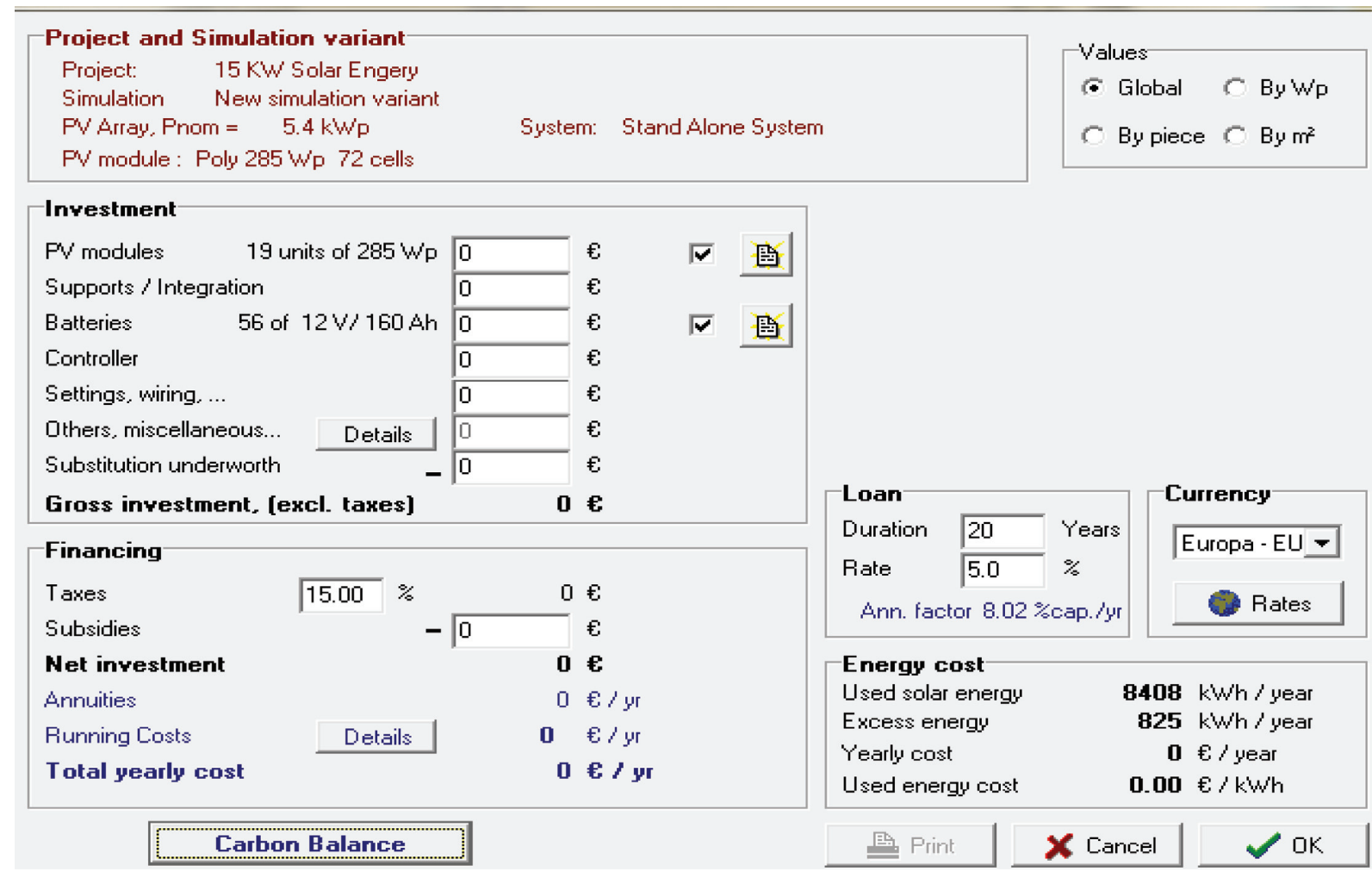

Figure 8: Cost estimation for the training mode.

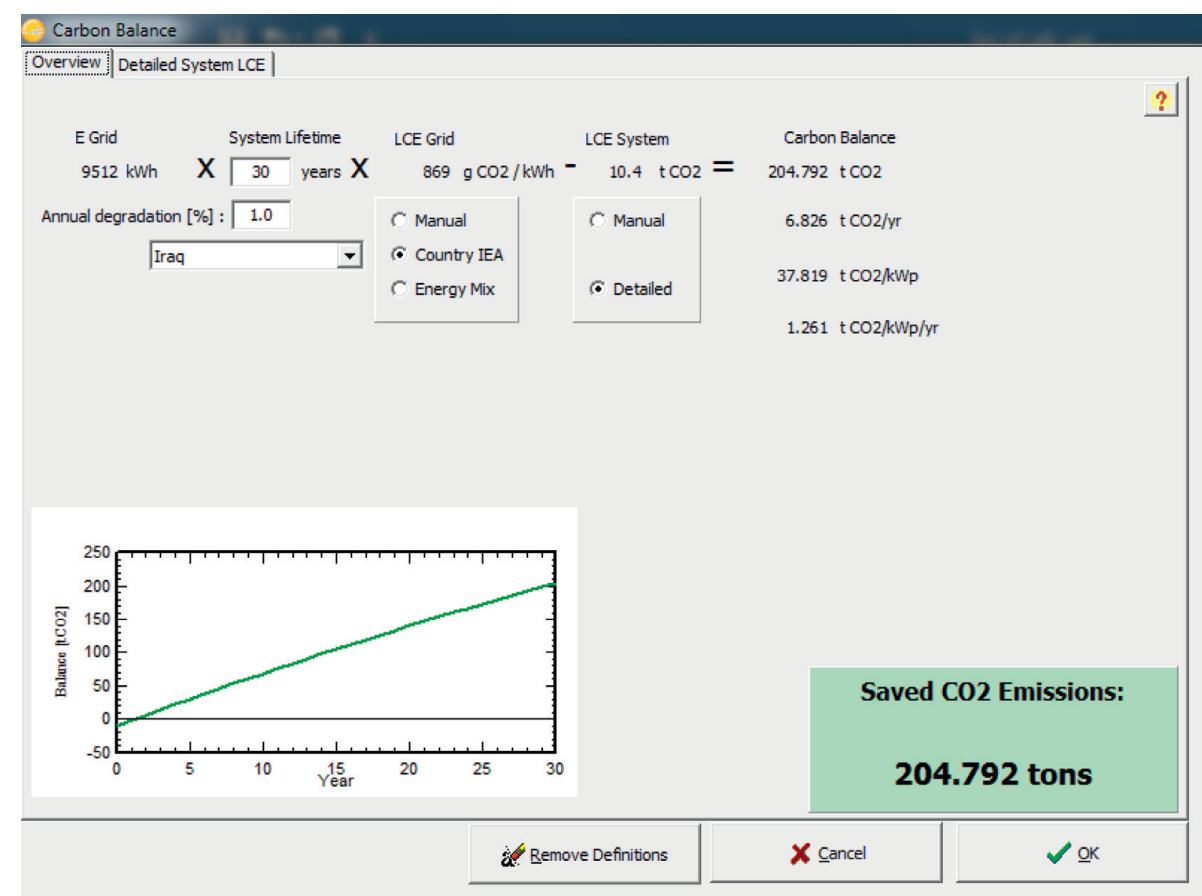

Figure 9: The proposed system of saving emission.

the solar capabilities and radiation throughout the months of the year which are extracted from the computer simulation program.

The system is implemented in two phases: the first is called training, which simulates the system with the data, and the second phase is the testing phase, where the system is connected to the local grid.

In terms of accuracy, the results of the proposed study are considered good when compared with previous studies as presented in Table 4. 
TABLE 2: Factors related to PV solar cells.

\begin{tabular}{|c|c|c|c|c|c|c|c|c|}
\hline & $\begin{array}{c}\text { GlobHor }(\mathrm{kWh} / \\
\left.\mathrm{m}^{2}\right)\end{array}$ & $\begin{array}{l}\text { DiffHor }(\mathrm{kWh} / \\
\left.\mathrm{m}^{2}\right)\end{array}$ & $\begin{array}{c}\text { T Amb } \\
\left({ }^{\circ} \mathrm{C}\right)\end{array}$ & $\begin{array}{l}\text { WindVel }(\mathrm{m} / \\
\mathrm{s})\end{array}$ & $\begin{array}{c}\text { GlobInc (kWh/ } \\
\left.\mathrm{m}^{2}\right)\end{array}$ & $\begin{array}{c}\text { DifSInc (kWh/ } \\
\left.\mathrm{m}^{2}\right)\end{array}$ & $\begin{array}{c}\text { Alb Inc (kWh/ } \\
\left.\mathrm{m}^{2}\right)\end{array}$ & $\begin{array}{c}\text { DifS/ } \\
(\mathrm{Gl})\end{array}$ \\
\hline January & 92.9 & 36.67 & 7.19 & 1.7 & 138.7 & 44.51 & 1.244 & 0.000 \\
\hline February & 112.7 & 42.81 & 10.34 & 2.1 & 153.3 & 51.21 & 1.508 & 0.000 \\
\hline March & 156.0 & 66.09 & 15.03 & 2.3 & 184.4 & 72.79 & 2.088 & 0.000 \\
\hline April & 180.2 & 82.17 & 19.30 & 2.3 & 184.4 & 84.40 & 2.412 & 0.000 \\
\hline May & 220.8 & 83.71 & 25.45 & 2.3 & 213.1 & 82.58 & 2.957 & 0.000 \\
\hline June & 237.2 & 72.87 & 30.50 & 2.5 & 218.0 & 70.44 & 3.165 & 0.000 \\
\hline July & 234.3 & 80.48 & 33.67 & 2.5 & 220.1 & 78.49 & 3.131 & 0.000 \\
\hline August & 218.6 & 71.19 & 33.07 & 2.1 & 223.3 & 73.36 & 2.926 & 0.000 \\
\hline September & 179.9 & 55.81 & 27.87 & 1.9 & 207.5 & 62.56 & 2.410 & 0.000 \\
\hline October & 145.2 & 46.39 & 22.84 & 1.6 & 191.8 & 56.20 & 1.944 & 0.000 \\
\hline November & 103.3 & 36.28 & 13.81 & 1.4 & 152.7 & 45.17 & 1.383 & 0.000 \\
\hline December & 84.1 & 33.60 & 9.05 & 1.5 & 129.6 & 41.47 & 1.126 & 0.000 \\
\hline Year & 1965.2 & 708.07 & 20.74 & 2.0 & 2222.2 & 763.21 & 26.295 & 0.000 \\
\hline
\end{tabular}

GlobHor: horizontal global irradiation; DiffHor: horizontal diffuse irradiation; T Amb: ambient temperature; WindVel: wind velocity; GlobInc: global incident in coll.; DifSInc: sky diffuse incident in coll.; Alb Inc: Albedo incident in coll.; DifS/G: incident sky diffuse/global ratio.

TABle 3: Performance related to PV solar cells derived from the simulation system.

\begin{tabular}{lcccccccc}
\hline & $\mathrm{Yr}\left(\mathrm{kWh} / \mathrm{m}^{2}\right.$.day $)$ & $\mathrm{Lu}$ & $\mathrm{Yu}(\mathrm{kWh} / \mathrm{kWp} / \mathrm{d})$ & $\mathrm{Lc}$ & $\mathrm{Ya}(\mathrm{kWh} / \mathrm{kWp} / \mathrm{d})$ & $\mathrm{Ls}$ & $\mathrm{Yf}(\mathrm{kWh} / \mathrm{kWp} / \mathrm{d})$ & $\mathrm{PR}$ \\
\hline January & 4.47 & 0.000 & 4.47 & 0.411 & 4.06 & 0.082 & 3.98 \\
February & 5.47 & 0.000 & 5.47 & 0.624 & 4.85 & 0.506 & 4.34 \\
March & 5.95 & 0.189 & 5.95 & 1.044 & 4.90 & 0.561 & 4.34 \\
April & 6.32 & 0.589 & 6.32 & 1.613 & 4.71 & 0.364 & 4.34 \\
May & 6.87 & 0.795 & 6.87 & 2.159 & 4.71 & 0.370 & 4.34 \\
June & 7.72 & 0.910 & 7.27 & 2.550 & 4.72 & 0.374 & 4.34 \\
July & 7.10 & 0.692 & 7.10 & 2.389 & 4.71 & 0.368 & 4.34 \\
August & 7.20 & 0.766 & 7.20 & 2.497 & 4.71 & 0.363 & 4.34 \\
September & 6.92 & 0.709 & 6.92 & 2.206 & 4.71 & 0.367 & 4.34 \\
October & 6.19 & 0.331 & 6.19 & 1.473 & 4.71 & 0.368 & 4.34 \\
November & 5.09 & 0.012 & 5.09 & 0.669 & 4.42 & 0.078 & 0.632 \\
December & 4.18 & 0.000 & 4.18 & 0.417 & 3.76 & 0.118 & 0.603 \\
Year & 6.09 & 0.418 & 6.09 & 1.509 & 4.58 & 0.325 & 3.65 \\
\hline
\end{tabular}

Yr: reference incident energy in coll.; Lu: normalized unused (full battery); Yu: normalized potential production; Lc: normalized array losses; Ya: normalized array production; Ls: normalized system losses; Yf: normalized system production; PR: performance ratio.

TABLE 4: Accuracy of the proposed method compared with existing methods.

\begin{tabular}{lcc}
\hline Researchers & Method used & Accuracy \\
\hline$[28]$ & Deep learning and IoT & 92.77 \\
{$[29]$} & Hybrid deep learning & 91.99 \\
{$[30]$} & CNN-LSTM & 93.51 \\
Proposed & New features: DNN & 94.65 \\
\hline
\end{tabular}

Results of the system reflect the performance and worth of the system. As a matter of fact, the complexity of design features extraction and directs the system to increase the hidden layer by suggesting new features according to the environmental change which is worthy.

\section{Conclusion}

In this study, a proposed method was designed for alternative energy, which is environmentally friendly, often needs management, and can be controlled to increase production efficiency. At the present time, due to the development in the field of software, especially deep learning, it has become possible for organizations to be managed electronically according to real-time data and outputs. Monitoring (the inverter device) through modern systems remains unable to respond immediately. From here, the use of deep learning has become important to obtain automatic control of the inverter. Many influences and variables hinder the work of the solar system, but by using smart methods, the system can be made instantly adaptive to the circumstances. During training mode, the system achieved good performance as reported in Section 5. The proposal for future work can be with automatic orientation towards sunlight and the calculation of features extracted from it in order to be processed.

\section{Data Availability}

All data used to support the findings of this study are included within the article.

\section{Conflicts of Interest}

The authors confirm that there are no conflicts of interest regarding the study of this paper. 


\section{Acknowledgments}

The authors extend their appreciation to the National Natural Science Foundation of China (31760181) and Yunnan Provincial Department of Education Fund (2020J0404) for funding this work.

\section{References}

[1] F. Weschenfelder, G. De Novaes Pires Leite, A. C. Araújo da Costa et al., "A review on the complementarity between gridconnected solar and wind power systems," Journal of Cleaner Production, vol. 257, Article ID 120617, 2020.

[2] S. Kumar, R. K. Saket, D. K. Dheer, J. B. Holm-Nielsen, and P. Sanjeevikumar, "Reliability enhancement of electrical power system including impacts of renewable energy sources: a comprehensive review," IET Generation, Transmission \& Distribution, vol. 14, no. 10, pp. 1799-1815, 2020.

[3] N. N. Opiyo, "How basic access to electricity stimulates temporally increasing load demands by households in rural developing communities," Energy for Sustainable Development, vol. 59, pp. 97-106, 2020.

[4] S. A. Mousavi, R. Asayesh Zarchi, F. Razi Astaraei, R. Ghasempour, and F. Mohammad Khaninezhad, "Decisionmaking between renewable energy configurations and grid extension to simultaneously supply electrical power and fresh water in remote villages for five different climate zones," Journal of Cleaner Production, vol. 279, Article ID 123617, 2021.

[5] J. A. M. Adaoag, M. E. A. Andres, P. D. Juan, C. A. R. Lagradilla, M. C. Pacis, and G. V. Magwili, "Determination of electrical energy costs for transmission networks using alternating current power transfer distribution factors (AC-PTDF)," in Proceedings of the 2020 4th International Conference on Electrical, Telecommunication and Computer Engineering (ELTICOM), September 2020.

[6] V. S. Tabar, M. Tarafdar Hagh, and M. Ahmadi Jirdehi, "Achieving a nearly zero energy structure by a novel framework including energy recovery and conversion, carbon capture and demand response," Energy and Buildings, vol. 230, Article ID 110563, 2021.

[7] S. Saint Akadiri, A. Adewale Alola, G. Olasehinde-Williams, and M. Udom Etokakpan, "The role of electricity consumption, globalization and economic growth in carbon dioxide emissions and its implications for environmental sustainability targets," Science of the Total Environment, vol. 708, Article ID 134653, 2020.

[8] O. Behar, D. Sbarbaro, and L. Moran, "Which is the most competitive solar power technology for integration into the existing copper mining plants: photovoltaic (PV), Concentrating Solar Power (CSP), or hybrid PV-CSP?" Journal of Cleaner Production, vol. 287, Article ID 125455, 2021.

[9] A. A. Du Plessis, J. M. Strauss, and A. J. Rix, "Short-term solar power forecasting: investigating the ability of deep learning models to capture low-level utility-scale photovoltaic system behaviour," Applied Energy, vol. 285, Article ID 116395, 2021.

[10] J. Yoo, B. Park, K. An et al., "Look-ahead energy management of a grid-connected residential PV system with energy storage under time-based rate programs," Energies, vol. 5, pp. 11161134, 2012.

[11] N. Jabalameli and M. A. Masoum, "Battery storage unit for residential rooftop PV system to compensate impacts of solar variations," Electrical and Electronics Engineering: An International Journal, vol. 2, no. 4, pp. 55-70, 2013.
[12] N. L. Tirupathamma, "Matlab simulation of grid connected PV system using hysteresis current control inverter," International Journal of Scientific Research in Computer Sciences and Engineering, vol. 5, pp. 13-20, 2014.

[13] A. Parikh, "Solar panel condition monitoring system based on wireless sensor network," International Journal of Science, Engineering and Technology Research (IJSETR), vol. 4, no. 12, pp. 4320-4324, 2015.

[14] S. Kurundkar, "Remote monitoring of solar inverter (an application of IoT)," American journal of Engineering Research (AJER), vol. 6, no. 7, pp. 70-74, 2017.

[15] H. Li, D. Yang, W. Su, J. Lu, and X. Yu, "An overall distribution particle swarm optimization MPPT algorithm for photovoltaic system under partial shading," IEEE Transactions on Industrial Electronics, vol. 66, no. 1, pp. 265-275, 2018.

[16] A. López-Vargas, M. Fuentes, and M. Vivar, "IoT application for real-time monitoring of solar home systems based on arduino with 3G connectivity," IEEE Sensors Journal, vol. 19, no. 2, pp. 679-691, 2019.

[17] S. Al-Dahidi, M. Louzazni, and N. Omran, "A local training strategy-based artificial neural network for predicting the power production of solar photovoltaic systems," IEEE Access, vol. 8, pp. 150262-150281, 2020.

[18] S. Abdul-Wahab, Y. Charabi, A. M. Al-Mahruqi, I. Osman, and S. Osman, "Selection of the best solar photovoltaic (PV) for Oman,” Solar Energy, vol. 188, pp. 1156-1168, 2019.

[19] A. Moradmand, M. Dorostian, A. Ramezani, A. Sajadi, and B. Shafai, "Fault-tolerant control of inverter for the integration of solar PV under abnormal conditions," The Journal of Engineering, vol. 11, pp. 1112-1122, 2020.

[20] Y.Sun, M. Peng, Y. Zhou, Y. Huang, and S. Mao, “Application of machine learning in wireless networks: key techniques and open issues," IEEE Communications Surveys \& Tutorials, vol. 21, no. 4, pp. 3072-3108, 2019.

[21] S. Aziz and M. Dowling, "Machine learning and AI for risk management," in Disrupting Finance, pp. 33-50, Palgrave Pivot, Cham, Switzerland, 2019.

[22] G. Sulong and A. Mohammedali, "Human activities recognition via features extraction from skeleton," Journal of Theoretical \& Applied Information Technology, vol. 68, p. 3, 2014.

[23] G. Sulong and A. Mohammedali, "Recognition of human activities from still image using novel classifier," Journal of Theoretical \& Applied Information Technology, vol. 71, p. 1, 2015.

[24] H. Liu and B. Lang, "Machine learning and deep learning methods for intrusion detection systems: a survey," Applied Sciences, vol. 9, no. 20, p. 4396, 2019.

[25] B. T. Atiyha, S. Aljabbar, A. Ali, and A. Jaber, “An improved cost estimation for unit commitment using back propagation algorithm," Malaysian Journal of Fundamental and Applied Sciences, vol. 15, no. 2, pp. 243-248, 2019.

[26] I. C. Konstantakopoulos, A. R. Barkan, S. He, T. Veeravalli, H. Liu, and C. Spanos, "A deep learning and gamification approach to improving human-building interaction and energy efficiency in smart infrastructure," Applied Energy, vol. 237, pp. 810-821, 2019.

[27] M. Husein and I.-Y. Chung, "Day-ahead solar irradiance forecasting for microgrids using a long short-term memory recurrent neural network: a deep learning approach," Energies, vol. 12, no. 10, p. 1856, 2019.

[28] E. L. Lydia, A. A. Jovith, A. F. S. Devaraj, C. Seo, and G. P. Joshi, "Green energy efficient routing with deep learning 
based anomaly detection for internet of things (IoT) communications," Mathematics, vol. 9, no. 5, p. 500, 2021.

[29] C. Zhang, J. Li, Y. Zhao, T. Li, Q. Chen, and X. Zhang, "A hybrid deep learning-based method for short-term building energy load prediction combined with an interpretation process," Energy and Buildings, vol. 225, Article ID 110301, 2020.

[30] T. Han, K. Muhammad, T. Hussain, J. Lloret, and S. Wook Baik, "An efficient deep learning framework for intelligent energy management in IoT networks," IEEE Internet of Things Journal, vol. 8, 2020. 